\title{
Microalgae Growth Modeling and Control for a Vertical Flat Panel Photobioreactor
}

\author{
Michael R. Buehner, Peter M. Young, Bryan Willson, David Rausen, \\ Rich Schoonover, Guy Babbitt, and Steve Bunch
}

\begin{abstract}
Microalgae have the potential to produce enough biofuels to meet the current US fuel demands. In order to achieve this potential, photobioreactors (PBRs) need to be developed that are efficient, scalable, and affordable. Models are an analytical tool that can be used to evaluate various PBRs. In this article, a dynamic model is developed for growing microalgae in a vertical flat panel photobioreactor (PBR) that may be used to measure PBR efficiency for various architectures independent of scale. The growth model is used to estimate the microalgae growth and byproduct production and consumption as a function of incident light. A feed-forward controller is developed that uses the estimated amount of $\mathrm{CO}_{2}$ consumed to determine the amount of additional $\mathrm{CO}_{2}$ to add to the system during photosynthesis. An overall controller structure that uses both feed-forward and feedback control is presented for growing microalgae inside a PBR.
\end{abstract}

\section{INTRODUCTION}

Microalgae can convert carbon dioxide $\left(\mathrm{CO}_{2}\right)$ into storage lipids that can be refined into biofuels. More $\mathrm{CO}_{2}$ is being produced now than in previous years, and there is limited supply of fossil fuels in the world. Under the right conditions, microalgae will utilize the excess $\mathrm{CO}_{2}$ being produced by human activity to produce lipids that may help supplement the limited fuel supply. There are two control objectives to this process, namely maximizing biomass growth and maximizing storage lipid production (i.e., the lipids that are favorable for biofuel production). The focus of this article is on improving biomass production by regulating key variables (e.g., $\mathrm{pH}$, dissolved $\mathrm{CO}_{2}$, dissolved $\mathrm{O}_{2}$, and temperature). While the use of models and controllers to improve lipid production are not discussed here, lipid production was achieved through the use of an appropriate microalgae strain [1].

A program of research sponsored by the National Renewable Energy Laboratory from 1978-1996 estimated that microalgae could produce lipids at the rate of 7,000 - 15,000 gallons/acre/year [2], almost 100X the current productivity of

This work was supported by Solix Biofuels

M. Buehner and P. Young are with the Department of Electrical Engineering, Colorado State University, Fort Collins, CO 80523, USA mbuehnereengr.colostate.edu and pmydengr. colostate.edu

B. Willson is with the Department of Mechanical Engineering, Colorado State University, Fort Collins, CO 80523, USA Bryan.Willson@colostate.edu

D. Rausen, R. Schoonover and S. Bunch are with Solix, $430 \mathrm{~N}$. College Ave., Fort Collins, CO 80524, USA rich.schoonoveresolixbiofuels.com, david.rausenesolixbiofuels.com and steve.bunchesolixbiofuels.com

G. Babbitt is with CZero, 321 Maple St., Fort Collins, CO 80521, USA guy.babbitteczero-solutions.com lipids from soy, at roughly 50-100 gallons/acre/year [1]. This means that microalgae could meet $50 \%$ of all transport fuel needs of the United States while using only $1.1 \%$ to $2.5 \%$ of the existing US cropping area [1]. While this is encouraging, there have been numerous problems with scaling up to a large production scale [3]. The primary challenge has been to design a PBR that is able to utilize intense light and maintain appropriate gas concentrations at a commercial scale (c.f., [1], [3], [4], [5], [6], [7], [8], [9].

Various PBR configurations (e.g., bubble columns, raceway ponds, and flat panel reactors) have been studied in [8]. Each configuration has its advantages and disadvantages. The trade-offs are finding reactors that utilize high light intensities well, can remove produced dissolved oxygen well, and scale well. A variety of linear and nonlinear models have been developed to address this for tubular reactors (c.f., [4], [5], [6], [7], [9], [10], [11], [12], [13], [14], [15]). However, there has been significantly less publications on flat panel reactors, which is the style of reactor addressed in this paper. Model based controls have been developed in [9], [16], [17], [18], [19], [20]. Most of these papers model growth as a function light using a Monod kinetics model. The Monod model describes how bacteria go through an exponential, linear, and decaying growth phases as they consume their nutrients. This idea is extended to how microalgae grow in a light limited closed PBR. This is an entirely empirical model that works well for some situations. In this paper, a scalable model is developed that addresses these phases by considering the physics of microalgae growth inside a vertical flat panel PBR that was developed at Solix Biofuels. The microalgae growth rate is modeled as a function of incident light. Based on the light driven dynamic growth model, an estimate of the amount of $\mathrm{CO}_{2}$ required for photosynthesis may be delivered as a feed-forward (FF) control input to the PBR. A feedback controller is used to maintain a constant $\mathrm{pH}$, which is also regulated using input $\mathrm{CO}_{2}$. A photo of the actual PBR used for these experiments is shown in Figure 1.

\section{METHOD}

In this section, an overall growth model is developed that may be used as a FF controller for $\mathrm{pH}$ regulation. The model is primarily physics-based with a few parameters that are fit from data. For the most part, these fitted parameters are efficiency parameters that may be used to compare the performance of different operating conditions and various PBR configurations. 


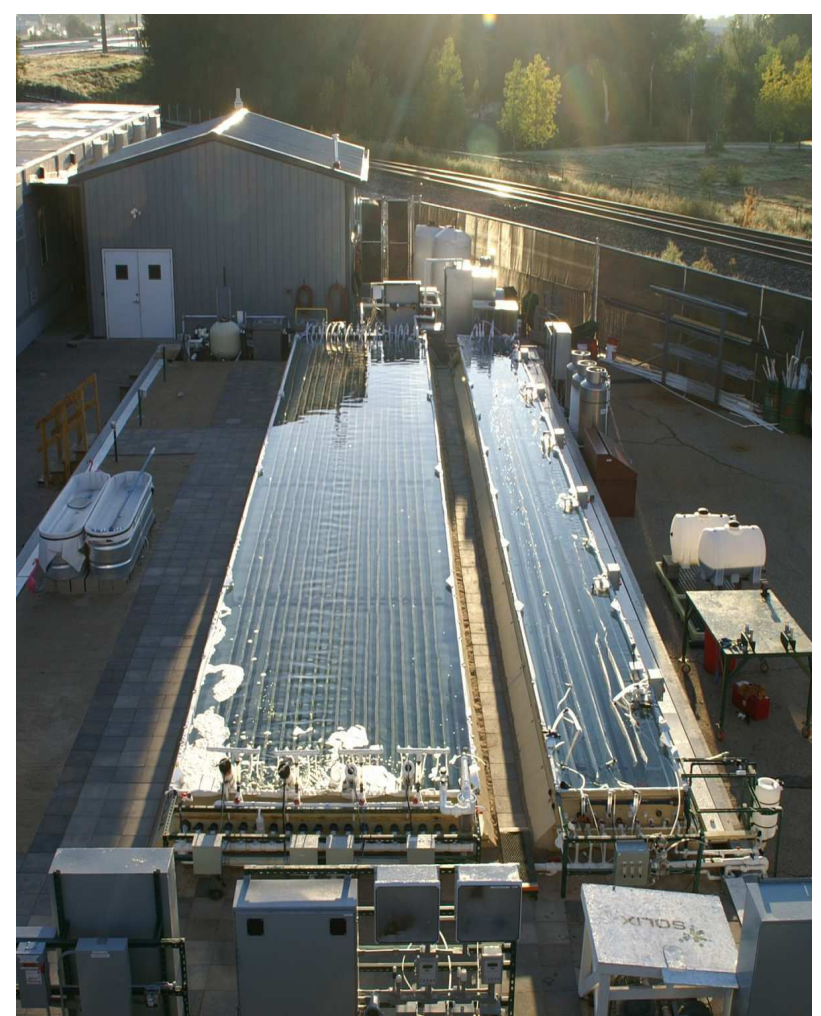

Fig. 1. Photobioreactor Test Bed at Solix Biofuels in Fort Collins, Colorado

\section{A. Photobioreactor Setup}

Fig. 1 shows one of the PBR test beds at Solix Biofuels in Fort Collins, Colorado. In the larger PBR bath (on the left), there are four PBRs. Each PBR consists of vertical flat panels submerged in the bath. Sensors are placed throughout the PBR to measure the amount of dissolved $\mathrm{O}_{2}(\mathrm{DO}), \mathrm{pH}$, and optical density (OD). The OD sensor correlates well to dry mass and was used to measure microalgae accumulation. Input gas streams of pure $\mathrm{CO}_{2}$ and air are continuously delivered through mass flow controllers (MFCs). These gas streams are then mixed and bubbled through the flat panels. This sparging is used to maintain elevated levels of dissolve $\mathrm{CO}_{2}$ by regulating to a lower $\mathrm{pH}$, remove $\mathrm{DO}$ produced by photosynthesis, and to mix the microalgae, which determines the light/dark cycle. The bath provided structure for the vertical flat panels and was used to regulate the temperature of the microalgae inside the vertical flat panels.

\section{B. Overall Dynamic Model}

There are three main subsystems that interact with each other, namely the incident light to the PBR, the microalgae cells that suspended in the media, and the media itself. The amount of incident light that the microalgae can utilize is a function of sun position and the amount mixing. As the microalgae grow, they interact with the media to remove nutrients and dissolved carbon while releasing dissolved oxygen. A gas mixture of air and $\mathrm{CO}_{2}$ is bubbled through the media to maintain the appropriate dissolved carbon level and to remove the produced dissolved oxygen through mass transfer. Since the amount of nutrients and dissolved gases in the media will effect the growth rate, these parameters are fed back from the media (water chemistry) model to the microalgae (photosynthesis) model. These phenomenon are captured in the overall PBR model in Fig. 2 that contains the three major subsystems, namely the light subsystem (red), the photosynthesis subsystem (green), and the water chemistry subsystem (blue). The details of each subsystem are described in the remainder of this section.

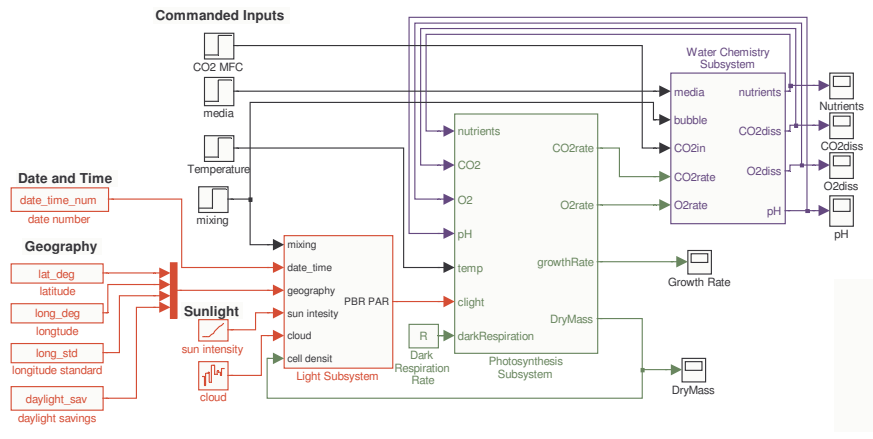

Fig. 2. Overall PBR Model.

All of the inputs to the model, except sunlight, may be commanded. This makes the control problem interesting, since sunlight is the main input that drives photosynthesis, yet enters the system as an exogenous input. Therefore, the control objective is to adjust the other parameters to maximize sun utilization.

\section{Incident Light Subsystem}

About $45 \%$ of the full spectrum of light is photosynthetically active radiation (PAR) which is the amount of light (in the $400 \mathrm{~nm}$ to $700 \mathrm{~nm}$ range) available for photosynthesis on earth. The incident light subsystem determines the amount of PAR that will reach the microalgae, which is a function of the number of PAR photons that enter the PBR bath, mixing, and PBR geometry. This may be expressed as

$$
I_{\mathrm{PAR}}=f_{1}\left(\mathrm{PAR}_{\text {bath }}, \text { mixing, geometry }\right) .
$$

The amount of PAR that enters the bath is a function of both the direct and diffuse light that are incident on the PBR bath, which was measured with a PAR sensor. For the model verification presented in this paper, the mixing (i.e., gas flow rate) and geometry were held constant. Therefore, the following simplified model of equation (1) was used.

$$
I_{\mathrm{PAR}}=\eta_{\mathrm{PBR}} \mathrm{PAR}_{\text {sensor }}
$$

Here, $\eta_{\mathrm{PBR}}$ is the efficiency of the PBR for a given mixing and geometry. The variable PAR sensor $_{\text {is the number of PAR }}$ photons measured by the PAR sensor. Currently, the term $\eta_{\mathrm{PBR}}$ is absorbed into the PAR utilization constant $K_{\mathrm{PAR}}$ in the next section. Therefore, $I_{\mathrm{PAR}}=\mathrm{PAR}_{\text {sensor }}$ is used for the current growth model. However, as more information becomes available about the effects of mixing and geometry, 
it will be incorporated into calculating a more accurate $I_{\mathrm{PAR}}$ term.

\section{Growth Subsystem}

The growth subsystem models the dynamics of the microalgae as they utilize photons from the sun, $\mathrm{CO}_{2}$, and nutrients to produce $\mathrm{O}_{2}$ and more microalgae. The rate at which microalgae grow depends on their ability to utilize the incident light and on the availability of nutrients. Assuming there are ample nutrients available, microalgae growth is primarily a function of input light. When there is an absence of light, the microalgae respire (i.e., utilize $\mathrm{O}_{2}$ and stored carbon as an energy source, which releases $\mathrm{CO}_{2}$ ). Respiration results in a loss of biomass. In the presence of light, the microalgae will both evolve $\mathrm{O}_{2}$ as they assimilate carbon from dissolved $\mathrm{CO}_{2}$ and respire $\mathrm{O}_{2}$ as they consume stored carbon; however, the growth from carbon assimilation will often dominate the metabolic process ${ }^{1}$. When the culture is sparse, there are an excess number of PAR photons that are not being utilized. Under this condition, microalgae will grow exponentially, since the produced algal mass will not be limited by available photons. At some point, the algal density will become great enough that all of the incident light will be utilized. At densities greater than this, the microalgae growth rate will be linear. As the density continues to increase, a smaller fraction of the microalgae will be able to receive the amount of light required for photosynthesis and respiration will be the dominant metabolic activity. As this happens, the total microalgae growth in the PBR will cease and eventually begin to decay. In the model, this feature is captured by saturating the density in the growth term. When the density gets above a critical density, labeled $m_{\text {dense, }}$, the amount of growth resulting from photosynthesis becomes linear while the density lost due to respiration remains exponential. These effects are described by the following nonlinear differential equation.

$$
\dot{m}_{\mathrm{algae}}=P \bar{m}_{\mathrm{algae}}-R m_{\mathrm{algae}}
$$

where

$$
\begin{aligned}
P & =K_{\mathrm{PAR}} I_{\mathrm{PAR}} \\
\bar{m}_{\text {algae }} & =\min \left(m_{\mathrm{algae}}, m_{\text {dense }}\right) \\
m_{\text {dense }} & =f\left(m_{\text {algae }}, \text { mixing, geometry }\right)
\end{aligned}
$$

The state variable $m_{\text {algae }}$ is the amount of microalgae inside the PBR and its derivative, namely $\dot{m}_{\text {algae, }}$ is the growth rate of microalgae inside the PBR. The productivity parameter $P$ is the specific growth rate at a given sun intensity. The term $K_{\mathrm{PAR}}$ is the sun utilization parameter that converts incident light, namely $I_{\mathrm{PAR}}$, into microalgae growth rate, and the constant $R$ is the rate of biomass loss due to respiration in the dark. The microalgae also respire while exposed to sunlight, so the respiration term is still appropriate during growing times. However, the rate of respiration is known to be greater during sunlight exposure.

\footnotetext{
${ }^{1}$ Microalgae contain the enzyme Rubisco that will utilize both $\mathrm{CO}_{2}$ and $\mathrm{O}_{2}$ as substrates.
}

This discrepancy is hard to measure directly. Instead, it is wrapped into the $K_{\text {PAR }}$ parameter (i.e., photorespiration results in a smaller sun utilization parameter). Finally, the parameter $m_{\text {dense }}$ is critical density above which the growth becomes linear.

As microalgae grow, they consume carbon, which they get from dissolved $\mathrm{CO}_{2}$ and other nutrients from their surroundings while releasing $\mathrm{O}_{2}$. In general, microalgae biomass is $50 \%$ carbon by dry weight [1]. A mole of $\mathrm{CO}_{2}$ has a mass of 44 grams and 12 of these grams come from carbon. Based on these premises, the expression that 1 gram of microalgae can fix 1.83 grams of $\mathrm{CO}_{2}$ may be derived as follows

$$
\frac{44 g \mathrm{CO}_{2} / \mathrm{mol}}{12 g \mathrm{C} / \mathrm{mol}} \frac{0.5 g \mathrm{C}}{g_{\text {algae }}}=\frac{11}{6} \frac{g_{\mathrm{CO}_{2}}}{g_{\text {algae }}}=1.83 \frac{g_{\mathrm{CO}_{2}}}{g_{\text {algae }}} .
$$

A simplified equation for photosynthesis is given by

$$
12 \mathrm{H}_{2} \mathrm{O}+6 \mathrm{CO}_{2}+\text { light } \longrightarrow \mathrm{C}_{6} \mathrm{H}_{12} \mathrm{O}_{6}+6 \mathrm{O}_{2}+6 \mathrm{H}_{2} \mathrm{O}
$$

This equation states that for every gram of $\mathrm{CO}_{2}$ consumed, there is a gram of $\mathrm{O}_{2}$ produced. While this is true, it does not account for all of the $\mathrm{O}_{2}$ that is produced. This results from the fact that $\mathrm{O}_{2}$ molecules come from splitting water, which provide energy for all of the metabolic processes inside the microalgae. Therefore, there is not a one-to-one correspondence of $\mathrm{O}_{2}$ molecules produced to $\mathrm{CO}_{2}$ molecules fixed. The excess energy that is not used to fix $\mathrm{CO}_{2}$ is used for other metabolic processes such as fixing nutrients from the surrounding media and cell repair. This is often echoed in the literature by the fact that it takes 8 photons of light to produce one $\mathrm{O}_{2}$ molecule, but that it takes 8-12 photons of light to assimilate a $\mathrm{CO}_{2}$ molecule (c.f., [21]). Assuming that 10 photons of light are required to fix one $\mathrm{CO}_{2}$ molecule, the amount of $\mathrm{O}_{2}$ produced will be

$$
\frac{32 g_{\mathrm{O}_{2}} / \mathrm{mol}_{\mathrm{O}_{2}}}{44 g_{\mathrm{CO}_{2}} / \mathrm{mol}_{\mathrm{CO}_{2}}} \frac{8 \mathrm{~mol}_{\mathrm{O}_{2}}}{10 \mathrm{~mol}_{\mathrm{CO}_{2}}} \frac{11}{6} \frac{g_{\mathrm{CO}_{2}}}{g_{\mathrm{algae}}}=1.07 \frac{g_{\mathrm{O}_{2}}}{g_{\text {algae }}} .
$$

Based on these assumptions, the $\mathrm{CO}_{2}$ consumption rate and $\mathrm{O}_{2}$ produced rate may be expressed in terms of the growth rate. In particular, the mass production and consumption rates of $\mathrm{CO}_{2}$ and $\mathrm{O}_{2}$, respectively, are

$$
\begin{aligned}
\dot{m}_{\mathrm{CO}_{2}(g / L / h)} & =1.83 \dot{m}_{\text {algae }(g / L / h)} \\
\dot{m}_{\mathrm{O}_{2}(g / L / h)} & =1.07 \dot{m}_{\mathrm{algae}(g / L / h)},
\end{aligned}
$$

In general, the relationships may be expressed as

$$
\begin{aligned}
\dot{m}_{\mathrm{CO}_{2}(\text { mass } / \text { time })} & =K_{\mathrm{CO}_{2}} \dot{m}_{\text {algae }(g / L / h)} \\
\left.\dot{m}_{\mathrm{O}_{2}} \text { (mass } / \text { time }\right) & =K_{\mathrm{O}_{2}} \dot{m}_{\text {algae }(g / L / h)}
\end{aligned}
$$

where, $K_{\mathrm{CO}_{2}}$ and $K_{\mathrm{O}_{2}}$ are the amount of gas consumed/produced per mass of microalgae growth and may be in units other than grams gas per gram microalgae. An example of this is when the amount of $\mathrm{CO}_{2}$ is measured in standard liters per minute (SLPM). Let $V_{\mathrm{PBR}(\mathrm{L})}$ be the volume of the PBR in liters and using the fact that there are 1.808 grams of $\mathrm{CO}_{2}\left(g \mathrm{CO}_{2}\right)$ per standard liter (SL), then $K_{\mathrm{CO}_{2}}$ 
may be expressed as

$$
\begin{aligned}
\dot{m}_{\mathrm{CO}_{2}(\mathrm{SLPM})} & =\frac{1 h}{60 \mathrm{~min}} \frac{\mathrm{SL}}{1.808 g_{\mathrm{CO}_{2}}} V_{\mathrm{PBR}(\mathrm{L})} 1.83 \frac{g_{\mathrm{CO}_{2}}}{g_{\text {algae }}} \dot{m}_{\text {algae }} \\
& =\frac{1.83 V_{\mathrm{PBR}(\mathrm{L})}}{1.808 \cdot 60} \dot{m}_{\mathrm{algae}(g / L / h)}
\end{aligned}
$$

\section{E. Water Chemistry Subsystem}

The water chemistry subsystem models both the dissolved gases and nutrients available to the microalgae in the media. The dissolved gases are a function of both the gases being delivered in by the MFCs and the internal gases being consumed and generated by the microalgae. The main purpose of sparging is to regulate the concentrations of dissolved $\mathrm{O}_{2}$ and dissolved $\mathrm{CO}_{2}$ through mass transfer. In general, the gas transfer rates may be modeled locally as a first order dynamic system. Due to the distributed nature of the system, the model would require many cascaded first order systems, which is common with process models. This phenomenon may be essentially captured by using a first order plus dead time model [22], which is the method used here.

When the media in the PBR is at equilibrium with air, there is about $7 \mathrm{mg} / \mathrm{mL}$ of dissolved $\mathrm{O}_{2}$ in the media, which is maintained through sparging when there is no growth. During high growth periods, dissolved $\mathrm{O}_{2}$ will build up in the system and is eventually purged at night. This is described by the following dynamic model.

$$
\dot{m}_{\mathrm{DO}}(t)=\frac{w_{\text {sparge }}}{\tau_{\mathrm{DO}}}\left(m_{\mathrm{DO}, \text { gas }}\left(t-\tau_{\mathrm{d}, \mathrm{gas}}\right)-m_{\mathrm{DO}}(t)\right)+\dot{m}_{\mathrm{O}_{2}}(t)
$$

Here, $w_{\text {sparge }}$ is the flow rate of gas into the PBR, $\tau_{\mathrm{DO}}$ is the lag time for mass transfer of DO between the media and sparging bubbles, $m_{\mathrm{DO} \text {,gas }}$ is the DO level that the media will equilibrate to, and $\dot{m}_{\mathrm{O}_{2}}$ is the rate of oxygen produced through photosynthesis. When sparging is turned off (i.e., $w_{\text {sparge }}=0$ ), then DO will build up in the system at the rate that it produced by photosynthesis. Once sparging is turned back on, the DO levels will equilibrate back to $m_{\mathrm{DO} \text {,gas }}$ with a lag time of $\frac{\tau_{\mathrm{DO}}}{w_{\text {sparge }}}$. The input gas stream is an air plus $\mathrm{CO}_{2}$ gas stream where the amount of added $\mathrm{CO}_{2}$ varies. This variation may change the equilibrium valve $m_{\mathrm{DO} \text {,gas }}$. There is a delay from when the $\mathrm{CO}_{2}$ concentration changes and when the new gas mixture arrives at the media, which is captured by the delay $\tau_{\text {d,gas }}$. For the model presented in this paper, it was assumed that $m_{\mathrm{DO}, \mathrm{gas}}=7 \mathrm{mg} / \mathrm{mL}$ independent of the $\mathrm{CO}_{2}$ concentration

An analogous method may be used to model the dissolved inorganic carbon (DIC), which is given in eqn (14).

$\dot{m}_{\text {DIC }}(t)=\frac{w_{\text {sparge }}}{\tau_{\text {DIC }}}\left(m_{\text {DIC,gas }}\left(t-\tau_{\text {d,gas }}\right)-m_{\text {DIC }}(t)\right)-\dot{m}_{\mathrm{CO}_{2}}(t)$

Here, $m_{\text {DIC,gas }}$ is the $\mathrm{CO}_{2}$ gas concentration required for a specific $\mathrm{pH}$. As $\mathrm{CO}_{2}$ is removed from the media through photosynthesis (i.e., $\dot{m}_{\mathrm{CO}_{2}}$ ), the value of $m_{\mathrm{DIC} \text {,gas }}$ will be increased to help replace the consumed $\mathrm{CO}_{2}$. Therefore, this value is always changing during active growth to maintain a constant $\mathrm{pH}$. Due to the distributed nature of the system, there is a delay of $\tau_{\text {d,gas }}$ between when the commanded $\mathrm{CO}_{2}$ concentration changes and when the $\mathrm{CO}_{2}$ reaches the media.

As $\mathrm{CO}_{2}$ dissolves in the media, it breaks down into different species, namely aqueous $\mathrm{CO}_{2}\left(\mathrm{CO}_{2(a q)}\right)$, carbonic acid $\left(\mathrm{H}_{2} \mathrm{CO}_{3}\right)$, bicarbonate $\left(\mathrm{HCO}_{3}^{-}\right)$, and carbonate $\left(\mathrm{CO}_{3}^{2-}\right)$. The combination of all of these species make up the total DIC. The amount of aqueous $\mathrm{CO}_{2}$, namely $\mathrm{CO}_{2(a q)}$, is a function of temperature and pressure, which is governed by Henry's Law. Based on the DIC and Henry's law, the following chemical equilibrium is reached.

$$
\mathrm{CO}_{2(a q)}+\mathrm{H}_{2} \mathrm{O} \rightleftharpoons \mathrm{H}_{2} \mathrm{CO}_{3} \rightleftharpoons \mathrm{H}^{+}+\mathrm{HCO}_{3}^{-} \rightleftharpoons 2 \mathrm{H}^{+}+\mathrm{CO}_{3}^{2-}
$$

The amount of each of carbonic acid, bicarbonate, and carbonate species determines the $\mathrm{pH}$. As $\mathrm{pH}$ increases the equilibrium shifts to the left and to the right as the $\mathrm{pH}$ decreases. As microalgae grow, $\mathrm{CO}_{2(a q)}$ is removed from the surrounding media, which causes the equilibrium to shift to the left and the $\mathrm{pH}$ to rise. Some strains of microalgae will also utilize bicarbonate as a carbon source. The microalgae still require $\mathrm{CO}_{2}$, which they get by splitting bicarbonate into $\mathrm{H}^{+}+\mathrm{HCO}_{3}^{-} \rightleftharpoons \mathrm{CO}_{2}+\mathrm{OH}^{-}$. The release of the $\mathrm{OH}^{-}$ also causes the $\mathrm{pH}$ to increase. It is unclear which method of carbon assimilation dominates the $\mathrm{pH}$ increase.

The addition of dissolved $\mathrm{CO}_{2}$ decreases the $\mathrm{pH}$ of the media. Since it can take 2-3 seconds for carbon to completely dissolve and only a fraction of the input $\mathrm{CO}_{2}$ dissolves before leaving the vent, there are some dynamics associated with the $\mathrm{pH}$ in the media, which are captured by the first order dynamics (transfer function) in eqn (16). The pH model is linearized about a $\mathrm{pH}$ of 7.3.

$$
\mathrm{pH}(t)=\frac{1}{\tau_{\mathrm{pH}}}\left(K_{\mathrm{pH}} m_{\mathrm{DIC}}(t)-\mathrm{pH}(t)\right)
$$

Here, $\tau_{\mathrm{pH}}$ is the lag time associated with the DIC settling into the appropriate species and $K_{\mathrm{pH}}$ is the conversion factor from DIC to $\mathrm{pH}$ units.

$\mathrm{CO}_{2}$ is not the only factor affecting $\mathrm{pH}$. Others have found that $\mathrm{pH}$ is also affected by calcium carbonate precipitation in the media and nitrogen assimilation, excess cation influx, excess anion flux, and organic assimilation and excretion by the microalgae [23]. However, $\mathrm{CO}_{2}$ input is the main controllable and measurable variable which has the most significant effect on $\mathrm{pH}$. This characteristic creates some challenges involving the separate control of $\mathrm{CO}_{2}$ and $\mathrm{pH}$, which is a topic of ongoing research.

\section{F. Feed-forward Controller}

One of the applications of the model is determine the amount of $\mathrm{CO}_{2}$ that is required by the microalgae and to supply it via FF $\mathrm{CO}_{2}$ control. Recall that the rate of $\mathrm{CO}_{2}$ consumption is directly related to growth rate. This was given in eqn 10. This $\mathrm{CO}_{2}$ consumption rate may be used as a FF input $\mathrm{CO}_{2}$ flow rate to the PBR. In practice, there is a nominal $\mathrm{CO}_{2}$ flow rate that is required to maintain $\mathrm{pH}$, which

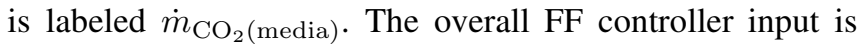
given by

$$
u_{\mathrm{CO}_{2}}^{F F}=\dot{m}_{\mathrm{CO}_{2}(\text { growth })}+\dot{m}_{\mathrm{CO}_{2} \text { (media) }}
$$


As with most FF control, a feedback controller is used to correct for model differences and to reject system disturbances. For the setup here, a PI controller was used to provide the feedback correction based on the desired and measured $\mathrm{pH}$. An overall block diagram of the controller is shown in Fig. 3.

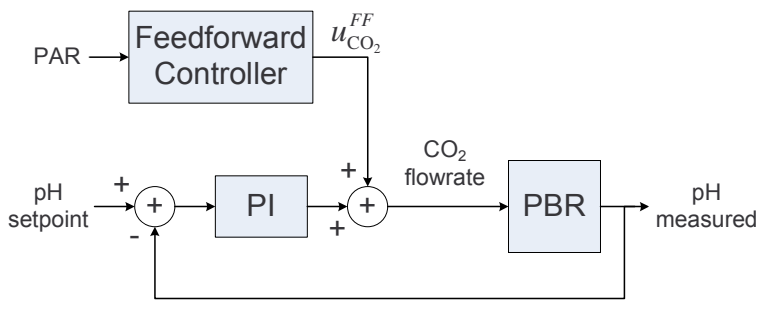

Fig. 3. pH Regulation using a Feed-forward plus Feedback Controller

\section{EXPERIMENT}

The $644 \mathrm{~L}$ PBR used for the following experiment is shown in Fig. 1. The PBR had four panels that were $17 \mathrm{~m}$ long, $0.33 \mathrm{~m}$ high, and $0.03 \mathrm{~m}$ thick. For the experiment described here, the microalgae strain Nannochloropsis oculata was used. The goal was to grow the microalgae culture up to maximum density in the shortest amount of time. Enough nutrients were provided at the beginning of the batch to make sure that the microalgae were not substrate limited. A combination of FF and feedback controller was used to regulate the $\mathrm{CO}_{2}$ delivery as described in Section II-F.

\section{A. Model Parameters}

A PAR sensor was used to measure the sun intensity at the bath. The methods outlined in Section II-C were used to determine the amount of light that entered the PBR bath in units of $\frac{\mathrm{mol}}{\mathrm{m}^{2} \text { hour }}$. Since the mixing and orientation were held constant, the term $\eta_{\mathrm{PBR}}$ in eqn 2 was grouped into the growth parameter $K_{\mathrm{PAR}}$.

The microalgae were able to utilize most of the light at low cell densities; however, as the density increased, the growth rate became linear. This is described by the saturation of $\bar{m}_{\text {algae }}$ in eqn 4 . For the experiments here, the biomass units have been normalized so that $m_{\text {dense }}=1$.

For the growth model used here, the temperature, nutrients, $\mathrm{pH}, \mathrm{O}_{2}$ concentration, and $\mathrm{CO}_{2}$ concentration were regulated externally. $\mathrm{O}_{2}$ removal was regulated by air sparging and the $\mathrm{CO}_{2}$ concentration was maintained by regulating the $\mathrm{pH}$. Therefore, the primary factor that affected growth was the PAR from eqn 2 . The model parameter $K_{\mathrm{PAR}}$ in eqn 4 captures the light utilization in units of $\frac{m^{2}}{\mathrm{~mol}}$. This parameter contains the effects of all of the variables that were held constant like mixing, orientation, temperature, nutrients, $\mathrm{pH}$, and dissolved $\mathrm{O}_{2}$ and $\mathrm{CO}_{2}$. This parameter along with the $\mathrm{FF}$ controller parameter $K_{\mathrm{CO}_{2}}$ were fit using a nonlinear least squares optimization.

The rate of respiration in the dark was calculated by examining the rate of respiration over multiple nights. This was accomplished take two points during the night and
TABLE I

VARIABLES USED IN FEED-FORWARD CONTROLLER

\begin{tabular}{|c|c|}
\hline Variable & Description \\
\hline$\dot{m}_{\text {algae }}$ & Modeled Growth Rate (OD/hour) \\
\hline$u_{\mathrm{CO}_{2}}^{F+}$ & FF CO \\
& Lommanded Input \\
\hline$K_{\mathrm{PAR}}$ & Light Utilization $\left(\mathrm{m}^{2} / \mathrm{mol}\right)$ \\
\hline$R$ & Rate of Respiration in the Dark (OD/hour) \\
\hline$K_{\mathrm{CO}_{2}}$ & $\mathrm{CO}_{2}$ Utilization (volume $\left.\mathrm{CO}_{2} / \mathrm{OD}\right)$ \\
\hline
\end{tabular}

assuming exponential decay. For example, if $m_{\text {algae }}(0)$ is the dry mass at $11 \mathrm{pm}$ at night (assuming that sunset is well before $11 \mathrm{pm})$ and $m_{\text {algae }}(5)$ is the dry mass at $4 \mathrm{am}$ the next day (assuming that sunrise is well after 4am), then the following holds

$$
m_{\text {algae }}(5)=m_{\text {algae }}(0) e^{-5 R},
$$

and $R$ may be calculated directly. By repeating this process over many days and averaging the results, a nominal $R$ value was obtained. The FF controller parameters are given in TABLE I.

A feedback PI controller was used to maintain the $\mathrm{pH}$ at 7.3. The controller gains were empirically tuned. An antiwindup digital PI controller was implemented to both prevent windup and to limit the controller actuation to the limits of the MFCs.

\section{RESULTS AND DISCUSSION}

Due to some software issues, only a feedback controller was implemented on the actual PBR shown in Fig. 1. For comparison, an estimate of what the FF controller would have predicted is plotted over the amount of $\mathrm{CO}_{2}$ required for $\mathrm{pH}$ regulation. The results of this controller are shown in Fig. 4.
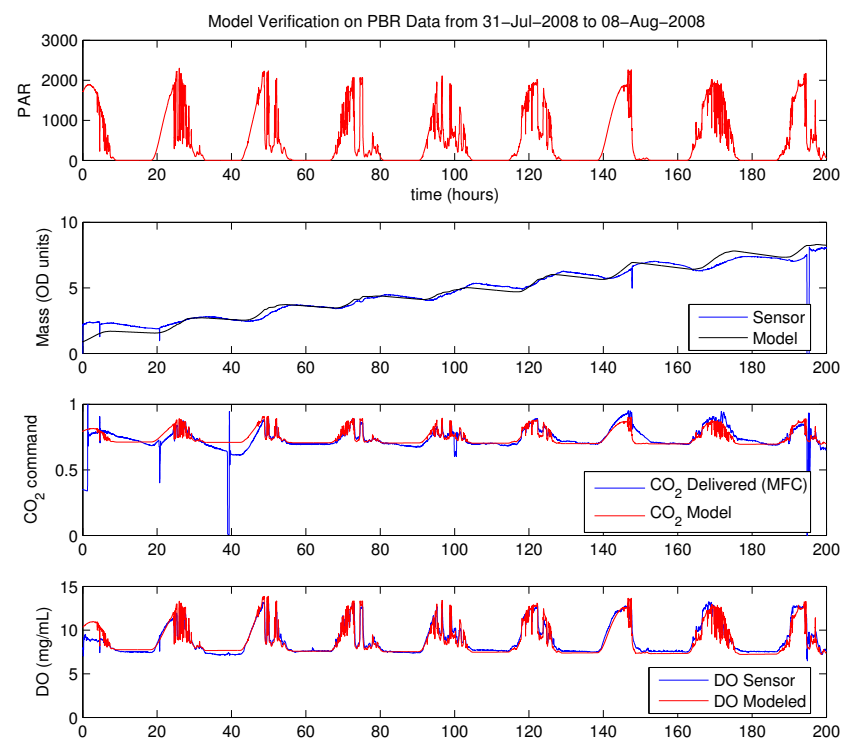

Fig. 4. Dynamic Model Verification.

Fig. 4 shows the both the growth model and the dissolved gas models over an entire batch. The first plot shows the PAR reading from an on-site sensor. The second plot shows the 
modeled and OD sensor measurement of microalgae mass. The third plot shows the amount of $\mathrm{CO}_{2}$ required to maintain a pH of 7.3 and a plot of what the FF controller would have commanded. The FF controller was able to capture the $\mathrm{CO}_{2}$ profile. During the day, the feedback controller was only able to regulate the $\mathrm{pH}$ to within 0.05 of 7.3. At night, the $\mathrm{pH}$ was within 0.01 of 7.3. It is assumed that the addition of the FF controller will provide tighter regulation during the day. The bottom graph shows the DO sensor reading and the DO model. All three models are able to capture the dynamics of the system using first order models.

For a given strain of microalgae, the rate of dark respiration, namely $R$, will be fixed. The only two parameters that will change with different operating conditions are $m_{\text {dense }}$ and $K_{\text {PAR }}$. The only parameter that will affect $m_{\text {dense }}$ is mixing since it will determine both the fraction of microalgae exposed to PAR photons and the duration of the exposure. Since there is an optimal light/dark cycle for microalgae [5], there is an optimal mixing with an associated maximal $m_{\text {dense }}$. Maximizing $m_{\text {dense }}$ will maximize that amount of time that the microalgae spend in the exponential growth phase. All of the other operating conditions will affect the sun utilization parameter, namely $K_{\mathrm{PAR}}$. A larger $K_{\mathrm{PAR}}$ means better sun utilization and hence more growth for a given amount of sun. Since the objective is to maximize growth, it is desirable to operate the PBR at the optimal temperature, nutrient level, dissolve oxygen level, dissolve carbon level, and $\mathrm{pH}$ level that will result in the largest $K_{\mathrm{PAR}}$. Maximizing $m_{\text {dense }}$ and $K_{\mathrm{PAR}}$ are topics of ongoing research.

\section{CONCLUSIONS AND FUTURE WORK}

A model for a vertical flat panel PBR was presented along with an example of how the model could be used for FF control. The model was developed independent of the actual PBR size or microalgae strain (i.e., it was built around densities and concentrations with parameters based on known theoretical relationships or fit from data). This allows for the same model to be used to evaluate the performance of a variety of PBR sizes, orientations, architectures, and various microalgae strains. It should be noted that different microalgae strains require different mixing, $\mathrm{pH}$ levels, temperatures, and nutrient levels. Ongoing modeling efforts will continue to develop methods for determining model parameters from first principles and experience with the physical PBRs.

As a part of the development process, a better understanding is needed of how the parameters held constant in eqns (1) and (4) affect the growth. Determining these effects and utilizing the model to test various operating conditions and PBR designs is crucial for commercial success. These are topics of ongoing research.

\section{ACKNOWLEDGMENTS}

This work was partially supported via a grant from Solix Biofuels.

\section{REFERENCES}

[1] Y. Chisti, "Biodiesel from microalgae," Biotechnology Advances, vol. 25, no. 3, pp. 294-306, 2007.

[2] J. Sheehan, T. Dunahay, J. Benemann, and P. Roessler, "A look back at the U.S. department of energy's aquatic species program-biodiesel from algae," National Renewable Energy Laboratory, Golden, Colorado, Tech. Rep. NREL/TP-580-24190, July 1998

[3] A. Richmond, "Microalgal biotechnology at the turn of the millennium: A personal view," Journal of Applied Phycology, vol. 12, pp. $441-451,2000$.

[4] J. Merchuk and X. Wu, "Modeling of photobioreactors: Application to bubble column simulation," Journal of Applied Phycology, vol. 15, pp. 163-169, 2003.

[5] M. Janssen, L. de Bresser, T. Baijens, J. Tramper, L. R. Mur, J. F. Snel, and R. H. Wijffels, "Scale-up aspects of photobioreactors: effects of mixing-induced light/dark cycles," Journal of Applied Phycology, vol. 12 , pp. 225-237, 2000.

[6] M. Janssen, J. Tramper, L. Mur, and R. Wijffels, "Enclosed outdoor photobioreactors: light regime, photosynthetic efficiency, scale-up, and future prospects," Biotechnology and Bioengineering, vol. 81, no. 2, pp. 193-210, 2003.

[7] A. Richmond and N. Zou, "Efficient utilisation of high photon irradiance for mass production of photoautotrophic micro-organisms," Journal of Applied Phycology, vol. 11, pp. 123-127, 1999.

[8] A. P. Carvalho, L. A. Meireles, and F. X. Malcata, "Microalgal reactors: A review of enclosed system designs and performances," Biotechnology Progress, vol. 22, pp. 1490-1506, 2006.

[9] J. Deschenes, A. Desbiens, M. Perrier, and A. Kamen, "On simultaneous control of biomass and metabolite concentrations in perfusion bioreactors," in DCDIS 4th Conference on Engineering Applications and Computational Algorithms, Guelph, Canada, 2005, pp. 663-667.

[10] F. Camacho Rubio, F. Garcia Camacho, J. M. Fernández Sevilla, Y. Chisti, and E. Molina Grima, "A mechanistic model of photosynthesis in microalgae," Biotechnology and Bioengineering, vol. 81, no. 4, pp. 459-473, 2003.

[11] F. Camacho Rubio, A. Sánchez Mirón, M. Cerón Garcia, F. Garcia Camacho, E. Molina Grima, and Y. Chisti, "Mixing in bubble columns: a new approach for characterizing dispersion coefficients," Chemical Engineering Science, vol. 59, no. 20, pp. 4369-4376, 2004.

[12] Y. Chisti, Airlift Bioreactors. Elsevier Applied Science, 1989.

[13] Y. Chisti, B. Halard, and M. Moo-Young, "Liquid circulation in airlift reactors," Chemical Engineering Science, vol. 43, pp. 451-457, 1988.

[14] Y. Chisti, M. Kasper, and M. Moo-Young, "Mass transfer in externalloop airlift bioreactors using static mixers," The Canadian Journal of Chemical Engineering, vol. 68, no. 1, pp. 45-50, 1990.

[15] N. Kurano and S. Miyachi, "Selection of microalgal growth model for describing specific growth rate-light response using extended information criterion," Journal of Bioscience and Bioengineering, vol. 100, no. 4, pp. 403-408, 2005.

[16] S. Celikovsky, S. Papacek, A. C. Herrera, and J. R. Leon, "Singular perturbation based solution to optimal microalgal growth problem and its infinite time horizon analysis," in 47th IEEE Conference on Decision and Control, 2008.

[17] M. Berenguel, F. Rodriguez, F. Acien, and J. Garcia, "Model predictive control of ph in tubular photobioreactors," Journal of Process Control, vol. 14, pp. 377-387, 2004.

[18] F. Camacho Rubio, F. Acién Fernández, F. Garcia Camacho, J. A Sánchez Pérez, and J. M. Fernández Sevilla, "Prediction of dissolved oxygen and carbon dioxide concentration profiles in tubular photobioreactors for microalgal culture," Biotechnology and Bioengineering, vol. 62, no. 1, pp. 71-86, 1999.

[19] L. Mailleret, O. Bernard, and J. P. Steyer, "Nonlinear adaptive control for bioreactors with unknown kinetics," Automatica, vol. 40, no. 8, pp. $1379-1385,2005$

[20] L. Mailleret, J.-L. Gouze, and O. Bernard, "Nonlinear control for algae growth models in the chemostat," Bioprocess and biosystems engineering, vol. 27, no. 5, pp. 319-327, 2005.

[21] H. W. Johnston, "The biological and economic importance of algae. part 4: the industrial culturing of algae," Tuatara : Journal of the Biological Society, vol. 22, pp. 1-105, 1976.

[22] E. F. Camacho and C. Bordons, Model Predictive Control. SpringerVerlag, London, 2004.

[23] R. J. Geider and B. A. Osborne, Algal Photosynthesis. Chapman and Hall, 1992. 